\title{
A Systematic Review of Robotics Research in Support of In-Home Care for Older Adults
}

\author{
Anas Abou Allaban ${ }^{1,+}+\mathbb{D}$, Maozhen Wang ${ }^{2, *,+}$ and Taşkın Padır ${ }^{1}$ \\ 1 Department of Electrical \& Computer Engineering, Northeastern University, Boston, MA 02115, USA; \\ abouallaban.a@northeastern.edu (A.A.A.); t.padir@northeastern.edu (T.P.) \\ 2 Department of Mechanical \& Industrial Engineering, Northeastern University, Boston, MA 02115, USA \\ * Correspondence: wang.mao@husky.neu.edu \\ $\dagger$ These authors contributed equally to this work.
}

Received: 15 December 2019; Accepted: 27 January 2020; Published: 30 January 2020

\begin{abstract}
The aging population is growing at an unprecedented rate globally and robotics-enabled solutions are being developed to provide better independent living for older adults. In this study, we report the results from a systematic review of the state-of-the-art in home robotics research for caring for older adults. This review aims to address two questions: (1) What research is being done towards integrating robotics for caring for older adults? (2) What are the research and technology challenges that robots are facing in the home? Sixty-three papers have been identified and studied in this review by following the Preferred Reporting Items for Systematic Reviews and Meta-Analyses (PRISMA) guidelines. Common themes that are consistent across the reviewed papers are distinguished and consolidated as follows: (1) Ambient assisted living, where smart home environments and physical support tools are studied; (2) Robot ecosystem, where robotic devices are used to provide various services; (3) Social interaction, where the social isolation problem has been targeted. We also summarize the results of similar literature reviews we came across during our search. The results of this study present the current research trends and technologies used in each category. The challenges and limitations of robotics applications are also identified. Suggestions for accelerating the deployment of robots at home for providing older adults with independent care in the home are presented based on the results and insights from this study.
\end{abstract}

Keywords: robotics for elder care; smart home; service robotics; assistive technology for older adults

\section{Introduction}

According to the United Nations, the population aged 60 or over is growing faster than all younger age groups globally [1]. As this trend continues for decades to come, elder care is becoming a grand societal challenge. Although for many older adults, aging in place is their initial preference and is seen to provide social and psychological benefits, their quality of life can be significantly reduced due to physical impairments and loneliness [2,3]. Thus, there is a great need to provide older adults with independent living at home. As the enabling technologies continue to emerge, we posit that home service robotics is a promising option to realize aging in place. Research in domestic service for elder care has been classified into different categories: rehabilitation robots, companion robots, health condition monitoring, anomaly detection, and so on.

In this article, we provide a systematic review of the emerging technologies in domestic service robotics for providing care to older adults. Our goal is two-fold: (i) provide a resource for the current state-of-the-art in this field and (ii) reflect on the current emerging trends to identify future research and technology development directions. Figure 1 presents a sample of robot systems extracted from the papers we reviewed. The purpose of this review is to analyze the effectiveness of the published 
technologies regarding home robotics and to identify issues that need to be further addressed. We seek to answer two questions in our review:

1. What research is being done towards integrating robotics for caring for older adults?

2. What are the challenges that robots are facing in the challenging home environments?

The purpose of these questions is to help us identify the pain points that older adults are experiencing and whether autonomous robot technologies can help alleviate these issues. We also aim to identify potential directions for improvements for the current inventory of autonomous robots.
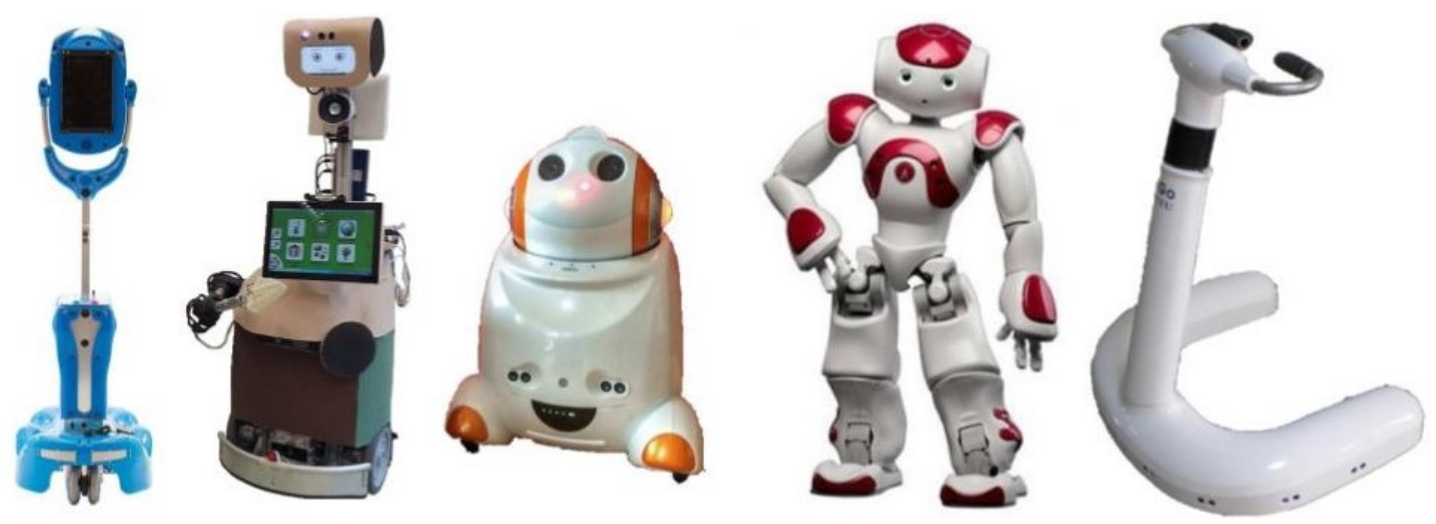

Figure 1. Sample robots extracted from the papers reviewed for this study. From left to right: Giraff [4], Hobbit [5], Matilda [6,7], Nao [8-11], iGo [12,13]. Various supports for older adults including telemonitoring, social interaction, and physical support are provided by these robotics systems.

\section{Methodology}

To evaluate the state-of-the-art in home service robotics research and to determine research directions for future efforts, we conducted a systematic literature review of papers published within the five years spanning from 2013 to 2018. Our systematic review follows the guidelines set out by Preferred Reporting Items for Systematic Reviews and Meta-Analyses (PRISMA) [14]. Unless otherwise noted, two reviewers have independently applied the criteria and recorded their critical appraisals.

\subsection{Study Selection and Criteria}

Our study selection was based on certain criteria that draw on the PICO method of framing a research question, summarized in Table 1. Although PICO is most often used in the medical field, we saw it applicable to our review methodology as it allowed us to hone in on the specific characteristics of the publications we are looking for. Our goal is to identify the literature pertaining to technologies related to smart homes, robotics, and cyber-physical systems. The literature had to provide empirical evidence that the technology did in fact support the older adults and addressed their needs.

Table 1. PICO criteria for selecting studies.

\begin{tabular}{lcc}
\hline$\#$ & Criteria & Key Element \\
\hline 1 & Elder Population & Population \\
2 & Smart Home & Intervention/Exposure \\
3 & Robotics & Intervention/Exposure \\
4 & Cyber Physical Systems & Intervention/Exposure \\
5 & Cyber/Software Solution & Intervention/Exposure \\
6 & State of the Art vs. Conventional Assistive Living Solutions & Comparator \\
7 & Acceptance Amongst Elderly & Outcome \\
8 & Address Needs from Senior's Perspective & Outcome \\
9 & Enhanced the Standard of Living & Outcome \\
\hline
\end{tabular}


Using the PICO criteria, we only focus on studies that reported older adults as their target population. Intervention is the means with which the specific paper approached the problem (e.g., smart home sensor, telepresence robot). A qualified study only needs to meet one of the intervention criteria, which are shown in Table 1. In other words, we include studies using either smart homes, robotics, or cyber physical systems. For the purposes of this review, the comparator criterion was used by the reviewers to determine whether a publication developed a novel method of approaching the problems associated with elder care and home robotics (e.g., neural net architecture, novel platform) or used previously studied and proven methods (e.g., SVM, commercial robot). Outcome was used to determine whether the results of the publication indicated an enhancement in the quality of life for the older adults, specifically, whether it enhanced their ability to do certain tasks or enabled them to do more when in an incapacitated state. It should be noted that a qualified study only needs to meet one of the outcome criteria, which are shown in Table 1.

The following databases were used to collect the research papers reviewed for this study:

- ScienceDirect,

- IEEE Explore,

- ACM Digital Library,

- $\quad$ Engineering Village.

These databases were selected based on a number of criteria:

- The collection of indexed publications, proceedings, and journals associated with robotics and their applications,

- Indexing of international publications,

- Accessibility within Northeastern University's library.

Indexing of international publications gives us a broader insight into whether geographical location plays a role in the research tools and methodologies for solving issues pertaining to robotics in elder care and smart home environments. The language, however, was restricted to English. Our search query was limited to a 5-year time interval (2013-2018) as robotics research in recent years has developed at a staggeringly fast rate. Many novel innovations have been reported and we would like to analyze how the state of the art has been applied to elder care in the home environments.

The search strings were selected to capture all research pertaining to assistive or home robots for elder care and smart home technologies for elder care. We use the asterisk term ${ }^{*}$ ) as a notation to indicate a prefix. Thus, "assis" becomes "assistive, assisted, ..." and all terms beginning with "assis*". To capture our intended publications, we used two search strings for each database with the following Boolean logic (or database equivalent):

- (home OR assis*) AND robot AND elder*,

- (smart AND home) AND elder*.

The search strings were applied to the title, abstract, and full text.

\subsection{Study Screening}

An inter-rater reliability test was initially performed between the two reviewers when selecting the criteria on a sample set of 50 papers. The purpose of the test is to make sure that two reviewers are having the same understanding of the criteria so that a similar score will be assigned to the same paper. Initial results showed a low reliability score (known as the kappa reliability score), and thus the criteria were redefined and made more specific. The second test showed a much higher score of 0.41 (corresponding as fair), and the criteria were finalized to what is now shown in Table 1.

After completing the inter-rater reliability test, we evaluated the collected records from all the database results. A flow diagram summarizing this approach is shown in Figure 2. The PICO criteria 
were applied to both abstract/title and full-text to extract papers for evaluation. The reasons for excluded papers during the full-text assessment stage are shown in the diagram (the reasons for excluded papers at abstract/title level are not provided by the tool we used, CADIMA [15].) Please note that one paper can be excluded for more than one reason. In addition, 775 records were collected from the initial set. Sixty-three records were identified as a result of this process for an in-depth and thorough evaluation. A table that outlines the category, approach and major outcome of the 63 papers included in this study can be found in Appendix A.

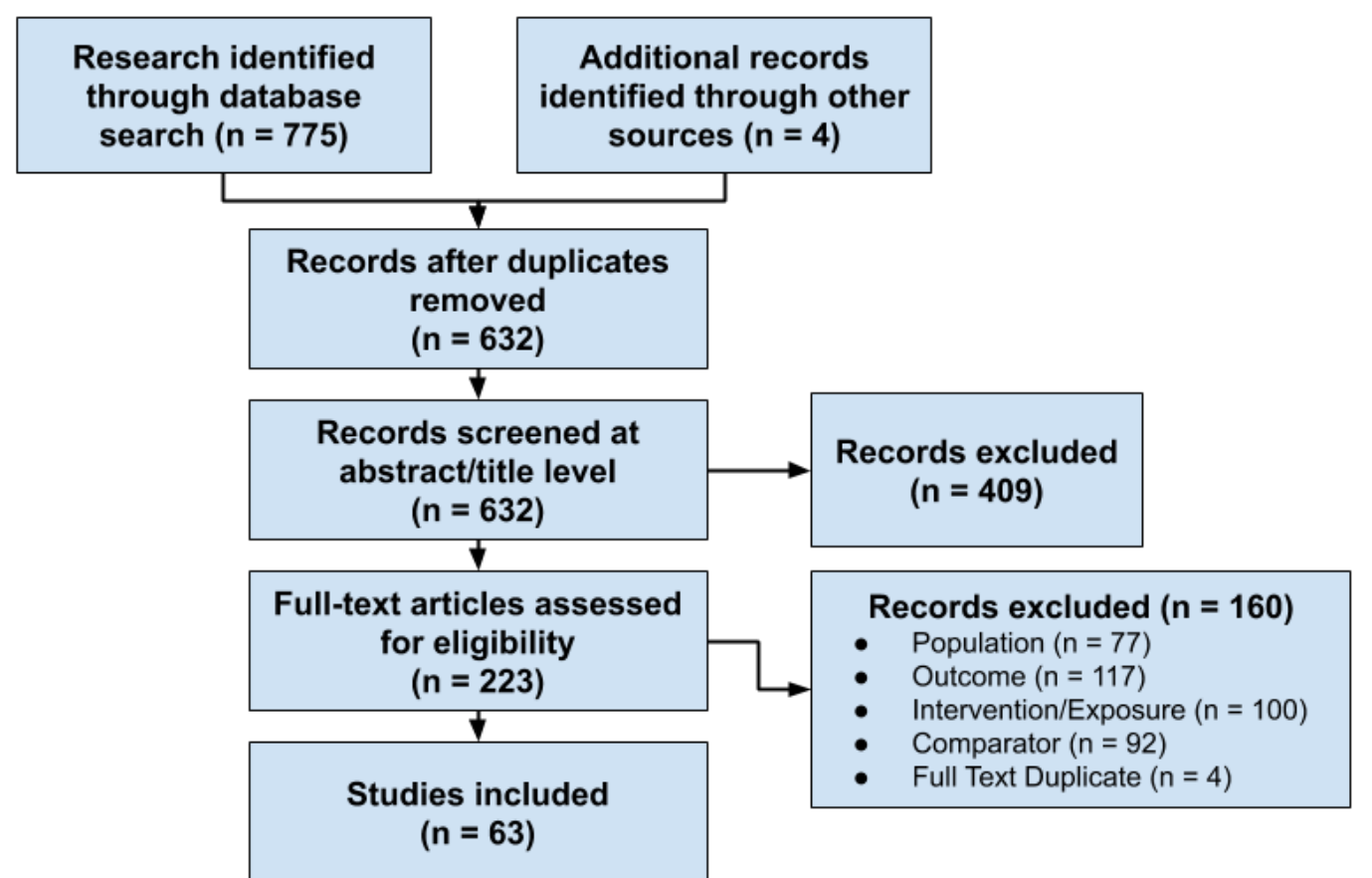

Figure 2. Flow diagram of the screening process. Please note that one record can be excluded for multiple reasons.

\section{Results}

During our investigation of the articles, there were certain themes that were consistent across the various research papers. We have consolidated these themes into three major categories: ambient assisted living (AAL), robot ecosystem, and social interaction. We further divided AAL into three subcategories to review relevant studies more specifically. The three subcategories of AAL are smart home, human activity recognition (HAR), and physical support tools. In the smart home category, we reviewed articles that attempt to improve the lift quality of older adults by utilizing a wireless sensor network. In the HAR category, different methods for analyzing older adults' activity patterns are reviewed. In the physical support tools category, we reviewed the development of robotics enhanced tools, such as smart walker and intelligent wheelchair. In the robot ecosystem category, studies that proposed novel designs or algorithms for robots in the context of elder care are reviewed. As for social interaction, studies that aim at reducing social isolation are studied. We also summarize the results of similar literature reviews we came across during our search. Both current research trends and drawbacks for each category are revealed and discussed. We also give suggestions based on our study results with the hope to lighten future studies and accelerate the deployment of robotics outside of laboratories.

Table 2 shows the distribution of reviewed articles among continents. The total number and distribution of records among the five categories are listed for each continent. The selected records come primarily from Asia and Europe. No studies originated from South America. We believe that the large number of research works from Asia is because of the rate at which the older adults population is growing relative to other locations.. Research from Asia focused mostly on physical support tools. 
Research from Europe primarily focused on social interaction and the development of novel platforms, such as Hobbit [5] and Giraff [4], that can perform multiple tasks for older adults. Research from North America, on the other hand, was distributed evenly among five categories. A summary of the distribution of the studies by year and category is presented in Figure 3. It should be noted that the table and figure only reflect the distribution of our articles in this study, which depend on the search strings and selection criteria.

Table 2. Global distribution of the evaluated research.

\begin{tabular}{ccccccc}
\hline Continent & Total & Smart Home & HAR $^{\mathbf{1}}$ & Physical Support & Robot Ecosystem & Social Interaction \\
\hline Asia & 23 & 3 & 4 & 10 & 2 & 4 \\
Europe & 20 & 2 & 3 & 2 & 6 & 7 \\
North America & 13 & 2 & 2 & 3 & 3 & 3 \\
Australia & 6 & 1 & 2 & 0 & 0 & 3 \\
Africa & 1 & 0 & 0 & 0 & 0 & 1 \\
\hline \multicolumn{7}{c}{${ }^{1}$ Human activity recognition. }
\end{tabular}

Papers by Category

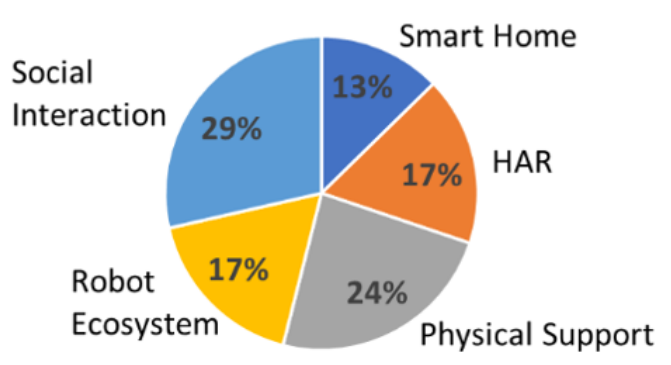

Papers by Year

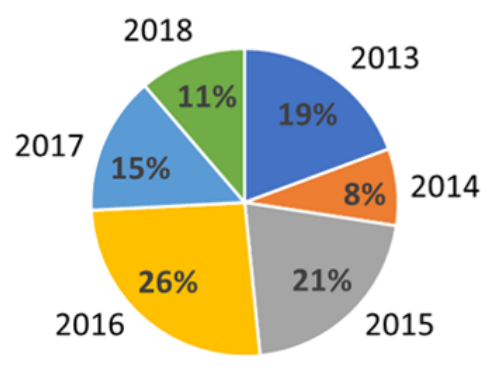

Figure 3. Distribution of papers based on category and year.

\section{Discussion}

\subsection{Ambient Assisted Living ( $A A L)$}

It is rare to find seniors these days who are completely self-reliant. Our physical and cognitive abilities obviously decline as we grow older; thus, we lose the ability to perform routine tasks we once took for granted. Robotics research has attempted to improve the lifestyle of the elder population through both smart home environments and physical means.

A smart home environment can provide older adults with a more comfortable and secure independent life by utilizing different auxiliary sensors. In [16], most representative European telemonitoring projects were studied. A telemonitoring system connects patients at home and remote therapists/caregivers through multi-sensor monitoring. Patients who live independently at home can thus access in time assistance or emergency alerts. Instead of connecting inhabitants with professional caregivers, many studies suggested the use of data collected from the smart home environment for daily activity recognition. Ref. [17] uses data collected from simple state-change sensors to classify 11 different underlying activities. By partitioning sensor observations into 60-second intervals and using a Probabilistic Latent Semantic Analysis topic model, an average accuracy of $76.15 \%$ is achieved for two different datasets. Various types of sensors including temperature, state-change, pressure, and cameras are used in [18]. Hidden Markov models are used to model human trajectories from cameras. The trajectories are then fused with sensor data and become the input for an SVM classifier. An average precision rate of $90 \%$ is claimed in this study. Ref. [19] instead uses sound information and achieves a $70.5 \%$ average recognition rate for activities that are modeled in a series of steps. With the help of accurate activity recognition, a spatiotemporal pattern describing human daily behaviors can then be derived via various machine learning methods $[20,21]$. The wellness of older adults can then be determined by analyzing the activity pattern [22-24]. Essentially, machine learning is used for both 
extracting features from sensor data and classifying activity patterns as normal or abnormal. A well trained model can achieve good accuracy for activity recognition and pattern classification. However, a great amount of data are needed to train the model; otherwise, bias can occur. Furthermore, since the sensor network in different smart homes may have different configurations, it is hard to train a general model that can fit the various smart home environments. In other words, a training process is needed for a new deployment, which is undesired considering time and data needed.

It is worth noting that the sensor network in the review papers uses no camera except [18], where cameras are used to extract trajectory. Instead, vision can also be used to recognize activities directly. In $[25,26]$, images from the first-person view are processed by computer vision and then fused with accelerometer data to recognize activities such as walking, climbing, cooking, etc. However, the recognition accuracy varies for different activities. On the other hand, in the computer vision community, vision based human skeleton detection and pose detection have achieved good progress with the development of depth camera and deep learning $[27,28]$. One good application of pose estimation regarding elder care is fall detection. With the progress in computer vision and review conducted in [29], we initially believed that vision based fall detection is already mature for applications. However, a good fall detection accuracy can only be achieved with multiple cameras looking from different views. Human skeleton detection accuracy can be greatly reduced due to self occlusion when looked at from the side, and fall detection is thus affected [30,31]. Ref. [30] chose not to use skeleton detection for fall detection due to this reason; however, multiple cameras (3) are still needed to achieve a robust result in their setting.

Physical support tools of different forms have been studied and proposed to improve their utility towards the elder population. Smart walkers, as an example, have gained many intelligent functionalities in recent years. A passive robot walker named i-Go is introduced in [12,13]. i-Go can interpret a user's motion intention from hand force input via a neural network and provide the desired driving force/torque to lead the way. A navigation scheme is then proposed to avoid moving obstacles on the path. Ref. [32] proposes another speed controller for a robot walker which determines the optimal speed by locating the user's legs using a laser range scanner. A depth image based gait tracking is used in [33] to ensure conformable usage of a robotic walker. A wheelchair, one of the most commonly used tools to enhance older adults' mobility, has also been enhanced with robotics. Advanced localization and navigation algorithms have been developed, which enables wheelchairs to autonomously navigate in both challenging indoor and outdoor environments [34,35]. Various input methods for controlling the wheelchair have also been investigated. From physical joystick to electroencephalogram, different possibilities have been explored by researchers to serve people with different types of disabilities [36]. Smart crane/staff [37] and exoskeleton [38] have also been enhanced with sensors and control algorithms to better secure the safety of older adults. Even smart shower systems [39] and sit-to-stand systems [40] have been proposed as a means of supporting elder's daily living and rehabilitation. The number of research projects with similar ideas is staggering yet, interestingly, very few of these ideas have been fully commercialized. One of the major concerns for older adults is the additional weight and size of robotics supporting tools comparing to regular tools. Even exoskeletons, a relative mature robotic solution with several available products on the market, are reported to be heavy and bulky, which makes it inconvenient to be used in daily life [41]. Older adults' unfamiliarity with technology also contributes to the low acceptance of robotic supporting tools [42]. Robustness is another factor worth mentioning. Even though researchers claimed good results for their designs, most of the experiments were carried out in relatively simple and controlled environments. It is necessary to make sure the tools provided to older adults can handle different scenarios in real life.

\subsection{Robot Ecosystem}

The various modules that could potentially be used to design a robot, such as visual sensors, natural language understanding, and human-machine interfaces, have slowly reached maturity over 
the last few years. What has not been well done though is the integration of all these systems into one platform. Robotic research platforms have been proposed $[5,43,44]$ which can complete simple user requests such as bringing objects or answering general queries; however, they are limited by their onboard functionality and hardware. The next step is to allow robots to leverage information from other technologies in their environment to perform more complex tasks and requests.

Ref. [45] for example, introduces IRMA, a "domestic robotic system" that finds misplaced items for the elderly. It is composed of navigation, perception, and communication layers that leverage a single knowledge representation module of its environment and execute tasks using a state machine. IRMA was able to understand and complete requested tasks $82.9 \%$ of the times. Its response times, however, were relatively high, taking on average $10.1 \mathrm{~s}$ for tasks involving describing an object in its knowledge base and $36.38 \mathrm{~s}$ to respond to a move command.

Ref. [46], on the other hand, investigates a similar problem to [45], but with finding people and not objects using a probabilistic approach. The mobile robot tours an environment and continuously updates its hypothesis on whether an individual is in a room or not based on visual observations. The authors highlight that image processing takes $4-5$ seconds, while the robot is stopped, to process the image and update and verify its hypotheses. While the processing time is much shorter than that of IRMA [45], it is still relatively expensive since the robot may need to react to other environmental changes or system requests. Moreover, this latency is not mission critical, yet it makes the robot less usable and effective in an actual domestic environment.

An approach to latency and compute constrained robots would be using a distributed system of robots instead. Ref. [47] states that "it is difficult to design a single robot to handle all types of tasks in [domestic] environments" and proposes the use of a multi-robot, distributed system to optimally allocate tasks. The results presented demonstrate a heterogeneous system of robots to coordinate effectively. This approach, however, is most probably not suitable for domestic environments due to the inherent costs associated with multiple robots and their maintenance, though such an approach should be considered in a larger environment such as an elder care facility or hospital.

In [48], the authors build a "smart room" that retain knowledge of all its elements with a knowledge database called a "Town Management System". This offloads all necessary computation to the various sensors in the room such as radio-frequency identification (RFID) tags and floor sensors. These sensors update environment information to the knowledge database and make it very simple for the robot to complete certain tasks. All the robot needs to do is query the knowledge database and it has all the information it needs. Like the multi-robot system approach, however, this is probably not feasible due to costs and requires a very controlled environment, which, even for a domestic environment for the older adults, may not be possible.

Robot architectures like IRMA are similar to the various robot systems surveyed in that various sensors are used to gather information about the environment and store it in some form of knowledge database, as shown in Figure 4. The recurring pattern in the literature, however, has been to either completely rely on local computation for executing tasks or completely offload computation to external sensors and servers. After surveying the literature, we believe that a combination of smart sensors and smart robots is necessary to have robots effectively complete tasks for older adults.

Robots alone cannot understand their environment and require the assistance of external sensors. However, they should also be able to act intelligently in the absence of certain sensors or external feedback. The surveyed literature did not seem to address robot behavior in these situations directly. The prior art usually skipped trial failures caused by network issues or ambiguous scenarios and simply restarted their trials. While this may be warranted in an experimental situation, it is indicative of the extensive research required to identify and propose first principles for robot design and architecture.

With the introduction of "smart", IoT, and connected devices in the home environment, a context and environmentally aware system could be designed. A system of simple devices can be used to assist more complex systems, such as mobile platforms, to complete tasks and would be more helpful towards the user as the complex systems are able to leverage the aggregated information. 
One approach to doing this is building an online knowledge base incrementally using abstract representations of the environment [44]. A topological graph of object locations in an environment, for example, during the mapping process while the robot is navigating a home would be very useful when an operator later requests the retrieval of an object. Smart home sensors could be used to determine where an operator is if the robot is called for support, enhancing navigation and minimizing the time looking for an operator.

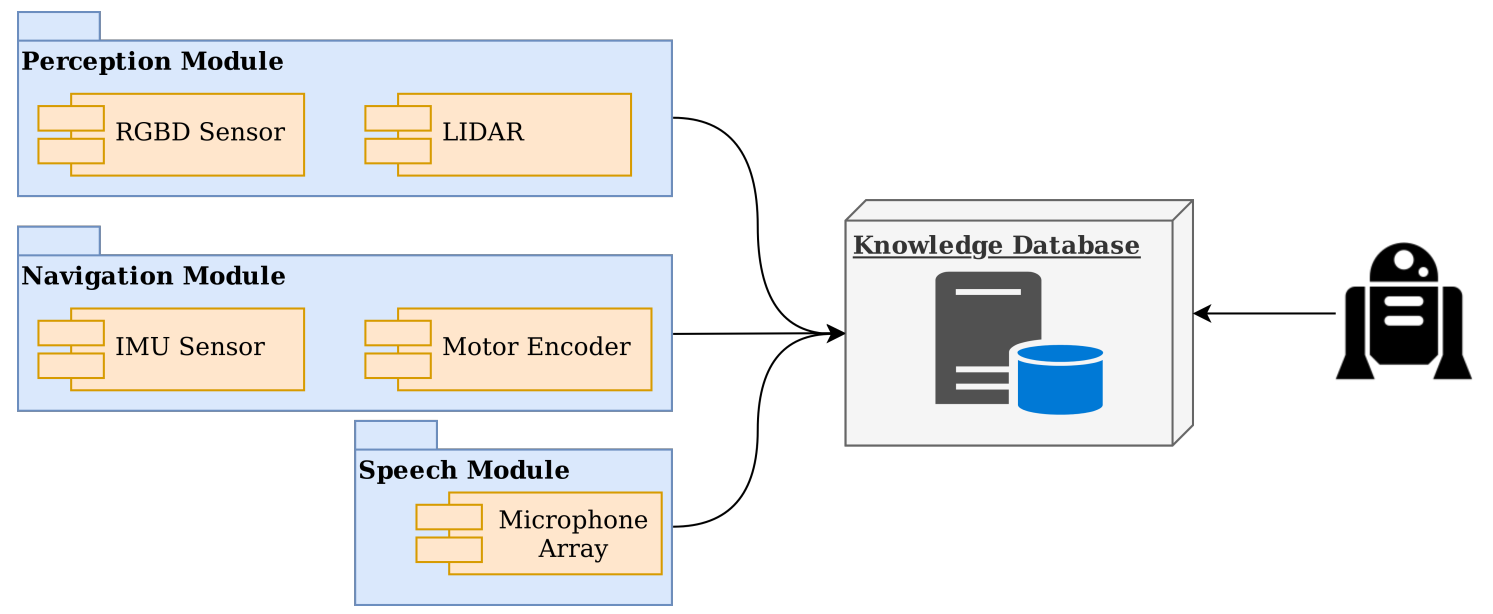

Figure 4. Architecture used by most robot platforms.

Some studies have gone as far to include body sensors as part of the ecosystem [49]. The research done in [49] on sensor fusion provided a wealth of data that allows for Dynamic Bayesian Network (DBN)-based event recognition and context detection. Auditory perception services, human position and vitals tracking were all recorded, allowing for enhanced detection of critical events such as speech and fall detection.

\subsection{Social Interaction}

One of the major issues that the elder population suffers from is limited social interaction. This usually leads to a feeling of loneliness, having a negative effect on mental health and sometimes promoting the development of Alzheimer's disease [50]. It can also lead to self-negligence since older adults are no longer interacting with other individuals. Researchers have attempted to address this by using technology as a means for social interaction. In [51], a systematic review was conducted on the various research approaches and technologies used to address social isolation. The two main trends identified were general information communication technology (ICT) and robotics. The studies using ICTs, however, were short term and no significant improvements in feelings of loneliness in the older adults were found. The research trials using robotic intervention techniques, specifically those with conversational capabilities, reported a decrease in social isolation and loneliness among seniors. This is because the robot provides a social presence, the ability to connect with family and friends, and depending on the platform, "talk therapy".

There are a wide variety of products already in the market designed with social interaction in mind, specifically via conversation, such as Amazon's Alexa and Google's Home. Both have had their market success but suffer from privacy concerns (see Mozilla Privacy Study [52]) from users. These products, however, attempt to behave more like assistants and less as a persona that one interacts with. A natural and environment aware conversation is a key factor for a positive interaction with a robot agent. Ref. [53] suggests a real-time correction system for natural language processing as a means of dealing with ambiguous and negative language. Such an interface has shown to promote collaborative behavior and interactions. If we assume that we are in a smart environment, we can utilize the concept of anchoring which connects sensor info with dialogue [54]. Here, a semantic system crawls through a 
database looking for items with similar attributes, creating an enriched and informed dialogue with a user.

The telepresence robot is one of the popular forms to perform social interaction with elder adults. Difference telepresence systems have been proposed in $[4,55,56]$. Although these systems have different features at the software level, they all share a similar hardware design that only has one screen for communication and a mobile base for moving around. This is fine if verbal communication is the only interaction method. However, the current research has shown that there needs to be some form of "sensory enrichment" [7], where the robot interacts not just verbally but through physical and emotive expressions as well. The evaluation of robot Hobbit in [5] also reveals that the multimodal interaction possibilities including gestures with the robot are favored by users. Companion robots are designed to perform interactions with elder adults in multiple forms, including visual, verbal, motions, emotive expressions, and physical contacts. Unlike the telepresence robot which connects older adults with other people for interactions, the companion robot interacts directly with the user. Companion robots of various appearances, from human-like to animal-like, can be found both in research and on the market. Companion robots are reviewed as effective in [57] and positive feedback for companion robots was reported by older adults in several experiments. Ref. [58] evaluates a seal-like robot PARO in a nursing home. Experiments with 10 older adults show that PARO has positive effects on increasing older adults' activity levels. Evaluation of social robot Matilta in an older adults care facility shows that the companion robot has had a positive impact on older adults' emotional well beings [6]. While experiments with humanoid robot NAO in [8] also show that participants were comfortable interacting with the robot, qualitative data from long-term trials (three months) reveal that participants' enjoyment with NAO might decrease over time. Similar concerns on long-term effects of companion robots were also suggested in [59].

Another approach of interaction through motions have been seen in the development of robotics coaches [9-11]. Robotic coaches have been designed to remind elder individuals to get up and get moving. Humanoid coaches have seen positive feedback and successful implementations in elder care facilities as they are able to demonstrate certain movements for older adults, minimizing the need for a human coach. Some researchers have gone as far as to attempt to correct movements via pose detection techniques, however, that resulted in negative feedback from users [9]. The main drawback of this approach is that not all stretches can be mimicked by the robot, resulting in a minimized set of exercise demonstrations. Other means of interaction could be through augmented reality (AR), virtual reality (VR), or mixed reality [60].

The socio-cultural barrier is another factor to be considered for social robot development. Experiments in [6] with Matilda showed that the robot must first cross the socio-cultural barrier for acceptance, in addition to being productive, useful, and resilient. This means that social interaction robots need to be designed with a cultural context in mind and not just an age demographic [61].

\section{Challenges and Future Directions}

To better answer our second question, we summarize the drawbacks of reviewed studies and challenges that robots are currently facing. In addition to challenges from a technical perspective, we are aware that potential ethical issues arising with the development of robotics for older adults are also critical. We thus also highlight the ethical concerns that we believe need to be considered particularly.

\subsection{Technical Challenges}

Design drawbacks or blind points that were overlooked in reviewed studies are summarized and presented by category. We believe it is important to resolve the following challenges to achieve the transition from lab to market for elder caring robots. 


\subsubsection{Ambient Assisted Living}

- Deployment of an activity recognition system

While machine learning has been proven as a good tool for tasks of classification, the need for data and training processes for different home configurations makes it hard for current systems to be deployed on a large scale. This is due to the property of machine learning: A well trained model can only deal with data collected from a particular sensor network. However, it is unpractical to use the same sensor network for all users as each of them may have a different home configuration.

- Experiments in less controlled environments

Robustness of technologies for older adults caring is especially crucial. Not only is robustness closely tied with older adults' safety, but users who are accustomed to their current tools also have little to no tolerance to failures of "new features" [62]. Most of the reviewed works only conducted experiments with proposed methods/tools in a controlled environment. Instead, we believe tests in real-life scenarios are necessary to achieve robust evaluation results.

\subsubsection{Robot Ecosystem}

- On-board computation capacity limitation

High response time of robots is reported in reviewed works due to limited onboard computation capacity $[45,46,49]$. The long processing time makes a robot agent less usable and effective. Cloud computing is helpful for this issue, but privacy needs to be carefully addressed.

- Data fusion from multiple sources

As we discussed in Section 4.2, some works have attempted to assist robot agents with data collected from environment sensors $[48,49]$. Robots alone cannot fully understand the dynamics of their environment due to limited perception ability. Information gathered from external environment sensors and older adults' inputs can thus be used to help robots better understand their surroundings and older adults' demands. Currently, most studies are treating robot platforms independently and omitting the chances of evolving robots with external data sources.

\subsubsection{Social Interaction}

- $\quad$ Personal preference of the user

Our reviews on social robots found that most studies treat older adults as a united object. Although some researchers have taken cultural context or age into consideration, very few of them attempt to match the personal preference or conditions of the user. The findings from [63-65] reveal it is important to match the user's personal preference since older adults would judge a social robot based on their own life circumstances, including both physical and psychological conditions. A social robot should thus have the ability to adapt its behavior to older adults with different individual problems, such as impaired vision or hearing.

- Novelty effect wears off over time

Current robots are not capable of self learning. Companion robots thus can only support programmed interaction modalities and contents. Over a long-term relationship, older adults are expected to get decreasing enjoyment from interactions with the same companion robot [8]. Attempts to provide users with non-repeating experience through companion robots have been seen on the market. For instance, the dog-like robot aibo is open to third-party developers and people can program new skills for aibo with provided API [66]. However, the effects of such attempts have not been well evaluated in the reviewed papers. 


\subsection{Ethical Challenges}

Ethical issues of using robotics for older adults caring will be more and more evident with the development of robotics technologies. Six widely agreed major ethical issues regarding deploying robots at home were identified in [67], which are: (1) reduced human contact, (2) loss of control, (3) loss of privacy, (4) restriction of liberty, (5) deception and infantilisation, and (6) issue of responsibility if things were to go wrong. Other ethical and regulatory concerns including competences of caregivers and robot safety have also been raised and discussed [68-70]. In addition to those well studied topics, we would like to elaborate on two ethical challenges that are revealed from reviewed works and draws less attention before.

- Knowledge Limitation of Older Adults

Findings from $[71,72]$ report that older adults are willing to tolerate a decrease in privacy in exchange for autonomy at home. Older adults seem to be happy living with technologies if they have control over their own information. However, how can we make sure that older adults can correctly interpret their privacy loss? Given the fact that many older adults are unfamiliar with technology, there could be a gap between older adults' understanding and the actual case regarding privacy loss. In other words, should consent made with only a smattering of knowledge be valid?

- Emotional Relationship with Robots

A long-term evaluation of socially-assistive robots shows that participants might engage in an emotional relationship with robots [8]. With the development of artificial intelligence, the behaviors of social robots will become more and more similar to humans and such emotional bonding between humans and robots will be more likely to happen. How should such relationships be judged? Should such connections between humans and robots in a deeply personal manner be encouraged? If not, can older adults possibly control their emotions to robots, which are going to be more and more intelligent in the future?

There is no immediate answer to certain ethical challenges, and there could be different answers for different applications or scopes. Nonetheless, we believe one efficient way to resolve ethical issues is involving older adults in the research or design process. Older adults are implicated but not present in the current development of robots [73]. By involving older adults in the process of research and design, researchers have the chance to take older adults' actual concerns into consideration and thus reduce the potential limitations of technologies. The ethical analysis method proposed in [70] also implies that, along with all stakeholders in aged care, the voice of care recipients is especially important.

\subsection{Future Directions}

Based on our review and the discussion above, we identify the following future directions to accelerate the realization of robotics applications for elder care.

First, in the category of AAL, physical support tools and fall detection can be viewed as mature technology for daily use. Technologies for physical support tools such as navigation, obstacle avoidance, and adaptive speed controllers are ready to use. In our opinion, what is left to be done for physical support tools are more close to engineering problems. For example, an optimized design regarding weight and size is needed to increase the acceptance rate among older adults and tests involving older adults to ensure the robustness are needed. As for vision based fall detection, high accuracy has been achieved in reviewed papers, but the need for multiple cameras reduces the ease of deployment. More work on reducing the obstruction from occlusion are needed. On the other hand, human daily activity recognition using smart home sensors is less mature due to the lack of generality for different smart home configurations. We also found that very different activity labels and validation protocols have been used in literature, which makes it difficult to compare and contrast research methods and results. We thus suggest to develop extensive shared datasets like [74] to enable 
benchmarking research. This can be helpful for both algorithm development and sensor network design since researchers can iteratively improve designs.

Second, to enable the widespread adoption of autonomous systems in domestic environments, research needs to focus on the architectural design of robot ecosystems. A combination of small, low-cost sensors that aggregate information to be processed in the cloud, offloading the computation for robots, can drive costs down and make it easy to integrate autonomous systems in a home environment. Figure 5 summarizes this by illustrating how both robots, users, and sensors all interact with each other through a "cloud" connected database.

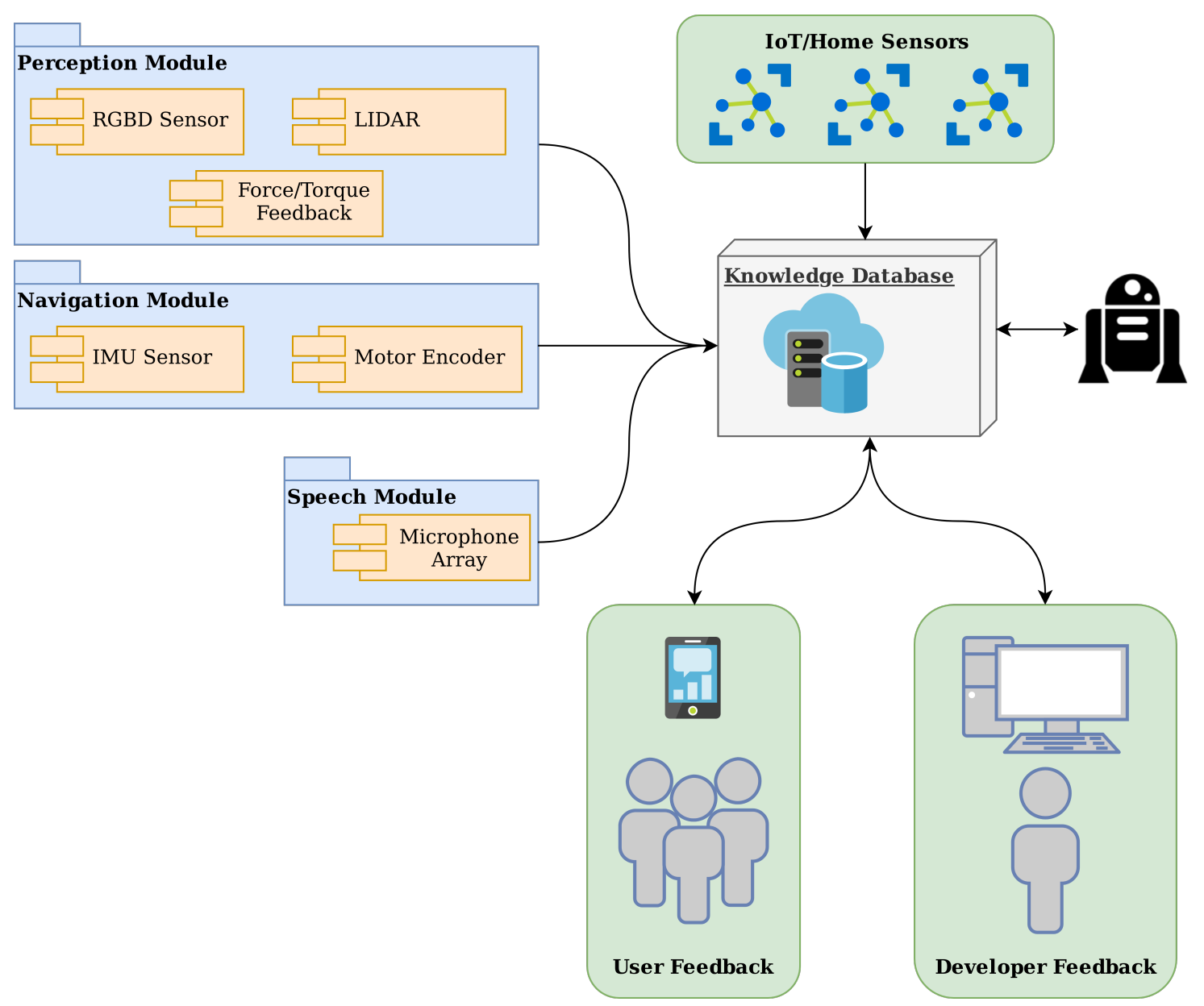

Figure 5. Proposed robot system architecture for domestic environments.

Third, to provide a better interactive experience for older adults, we suggest developing verbal interaction models for different cultures and ages to improve robotics applications in social interactions. Verbal communication as the most common form of interaction can become an efficient tool to break the socio-cultural barrier and can be helpful to erase elder people's insecure with robots. In addition, we suggest conducting a long-term evaluation of social robots among older adults with two purposes: understanding the effects of repeated interactions for older adults; finding and evaluating approaches that aim to reduce repeated interactions with social robots.

\section{Conclusions}

In this paper, we presented our results from a systematic review on robotics research in the area of domestic older adults care. Current research trends have been identified and categorized into three themes. Challenges and future directions for each category are also presented. 
A great number of studies have been conducted on integrating robotics technologies into home and progress has been made in the past decade. Certain autonomous systems and technologies can be seen as close to mature from a research perspective such as physical support tools and fall detection. However, engineering problems such as product design and comprehensive tests are still needed before actual deployment. More complex systems, such as daily activity recognition in the smart home and mobile robot platforms, require more research.

A multidisciplinary approach is necessary for robotics to thrive in the area of elder care. Expertise from engineering, medical, social science, and legal disciplines are needed to address all the ethical, legal, and technical features to support robotics assisted aging in place.

Author Contributions: A.A.A. and M.W. designed the review process, searched, and screened and analyzed reviewed literature; A.A.A. and M.W. wrote the manuscript; T.P. supervised, reviewed, and edited the manuscript. All authors have read and agreed to the published version of the manuscript.

Funding: This research is supported by the National Science Foundation under Award Nos. 1544895, 1935337 and Arcelik Research Grant. This research is also supported through a partnership with Toyota Motor Corporation.

Conflicts of Interest: All the authors declare no conflict of interest. The funders had no role in the design of the study; in the collection, analyses, or interpretation of data; in the writing of the manuscript, or in the decision to publish the results. 


\section{Appendix A}

Table A1. Summary of reviewed studies.

\begin{tabular}{|c|c|c|c|c|}
\hline Study & Year & Category & Approaches & Major Outcome \\
\hline$[75]$ & 2017 & AAL & Smart Home Arch. & $\begin{array}{l}\text { Prototype system design with XBees and Galileo. Off the shelf sensors to detect light, door opening, etc. } \\
\text { Creating DB for history and app for GUI. Environment monitoring instead of monitoring the status } \\
\text { of residents. }\end{array}$ \\
\hline [18] & 2016 & AAL & Smart Home Arch. & $\begin{array}{l}\text { Phidgets sensor system to house appliances. RGBD sensors, small monitoring robot. Activity detection } \\
\text { for elderly with alzheimers and mild cognitive impairment. Elderly participants prefer a robot platform } \\
\text { to a surveillance system. }\end{array}$ \\
\hline [76] & 2018 & AAL & Machine Learning (ML) & $\begin{array}{l}\text { Method to predict one's functional health from unobtrusively collected behavioral data inside their own } \\
\text { apartments. It showed that it is possible to detect resident's functional health decline using unobtrusively } \\
\text { collected in-home behavioral data. However, the shown results are not accurate and need improvement. }\end{array}$ \\
\hline [16] & 2014 & AAL & Telemonitering & $\begin{array}{l}\text { Comparison of different telemonitering systems; a global architecture that summarizes studied projects; } \\
\text { issues of current systems: privacy, stable connection and generality for different diseases }\end{array}$ \\
\hline [30] & 2016 & AAL & Computer Vision (CV) & $\begin{array}{l}\text { A RGB-D dataset for human fall recovery. A modified DSTIP + DCSF method for fall recovery subactivity } \\
\text { recognition using depth images. }\end{array}$ \\
\hline [31] & 2015 & $\mathrm{AAl}$ & Computer Vision & $\begin{array}{l}\text { Depth image based fall detection. Equipped the depth camera on mobile robot to minimize the blind area } \\
\text { of camera. The accuracy reduces due to self occlusion. }\end{array}$ \\
\hline [29] & 2015 & AAL & Review & $\begin{array}{l}\text { A review on fall detection algorithms. The advantage and disadvantage of method based on acceleration } \\
\text { sensor, combined sensors and non-accelerometer are analyzed. A single acceleration sensor has low } \\
\text { accuracy. Video based fall detection has better accuracy but with the limitation of price and } \\
\text { privacy problems. }\end{array}$ \\
\hline [71] & 2015 & AAL & Review & $\begin{array}{l}\text { Consulting with elders in design is critical. Elders willing to tolerate some loss in privacy in exchange for } \\
\text { autonomy at home. Equipment should be reliable, non-intrusive, and have control over data. }\end{array}$ \\
\hline [24] & 2013 & AAL & Smart Home Arch. & $\begin{array}{l}\text { A smart home arch. and algorithm to monitor the usage and household appliances and forecast the } \\
\text { wellness of users based on usage data }\end{array}$ \\
\hline [17] & 2016 & HAR & ML & Human activity recognition method using a pLSA topic model. \\
\hline
\end{tabular}


Table A1. Cont.

\begin{tabular}{|c|c|c|c|c|}
\hline Study & Year & Category & Approaches & Major Outcome \\
\hline [25] & 2018 & HAR & $\begin{array}{l}\text { Wearable Devices, } \\
\text { CV, ML }\end{array}$ & $\begin{array}{l}\text { A system that fused data from egocentric vision and accelerameter to perform activity recognition. } \\
\text { A framework for semantic representation and interpretation for detected activities. An application for } \\
\text { both users and clinicians to check detected results. }\end{array}$ \\
\hline [26] & 2015 & HAR & $\begin{array}{l}\text { Wearable Devices, } \\
\text { CL, ML }\end{array}$ & A smart-glass and algorithm for activity recognition using egocentric video and head acceleration data. \\
\hline [20] & 2018 & HAR & ML & $\begin{array}{l}\text { A two phases approach called CARER (Complex Activity Recognition using Emerging patterns and } \\
\text { Random forest) for activity recognition. In the training phase, emerging patterns and features are } \\
\text { extracted. A correlation matrix is constructed. In the detection phase, the traces are segmented and } \\
\text { activities are recognized from the segmented results. }\end{array}$ \\
\hline [77] & 2015 & HAR & $\begin{array}{l}\text { Smart Home Arch., } \\
\text { Wearable Devices, ML }\end{array}$ & $\begin{array}{l}\text { Using both environment sensors and wearable sensors to recognize human activities. The two types of } \\
\text { sensors are fused to construct a hierarchical activity recognition model. High accuracy of } 97.48 \% \text { is } \\
\text { achieved. }\end{array}$ \\
\hline [21] & 2016 & HAR & ML & Find sequential relations and temporal correlations among activities to predict the next activity of a user \\
\hline [22] & 2018 & HAR & ML & $\begin{array}{l}\text { A learning automaton (LA) based on variable structure stochastic automata to achieve fast and accurate } \\
\text { pattern recognition and tracking. In addition, the bias of the proposed LA can be tuned. }\end{array}$ \\
\hline [19] & 2015 & HAR & ML & $\begin{array}{l}\text { The design and test of a complementary HAR system based on the analysis of environmental sounds. } \\
\text { Accuracy rate needs improvement. }\end{array}$ \\
\hline [23] & 2017 & HAR & Smart Home Arch., ML & $\begin{array}{l}\text { A sensing system and algorithm that can detect normal and depression mental conditions based on } \\
\text { classification using extracted activities of daily life. }\end{array}$ \\
\hline [78] & 2017 & HAR & Computer Vision & A human action recognition method based on human's skeleton joints information and object detection. \\
\hline [37] & 2016 & $\begin{array}{l}\text { Physical } \\
\text { Support }\end{array}$ & Staff & A smart staff that can vary its length according to the height of elder and the slope of the ground. \\
\hline [79] & 2016 & $\begin{array}{l}\text { Physical } \\
\text { Support }\end{array}$ & Supporting Robot & $\begin{array}{l}\text { Modeling human and robot kinematics for a sit to stand support robot. Monitoring motion of user for } \\
\text { optimal sit to stand trajectory. }\end{array}$ \\
\hline [40] & 2016 & $\begin{array}{l}\text { Physical } \\
\text { Support }\end{array}$ & Supporting Robot & A assistant stand-up robot that can predict the elder's trajectory during the stand-up motion. \\
\hline [12] & 2016 & $\begin{array}{l}\text { Physical } \\
\text { Support }\end{array}$ & Walker & A smart walker control scheme that can avoid dynamic obstacles. \\
\hline
\end{tabular}


Table A1. Cont.

\begin{tabular}{|c|c|c|c|c|}
\hline Study & Year & Category & Approaches & Major Outcome \\
\hline [35] & 2016 & $\begin{array}{l}\text { Physical } \\
\text { Support }\end{array}$ & Wheelchair & A control system for wheelchair to track the reference trajectory on asphalt and gravel roads. \\
\hline [13] & 2016 & $\begin{array}{l}\text { Physical } \\
\text { Support }\end{array}$ & Walker & $\begin{array}{l}\text { Developed a low-cost force sensing grip. Proposed a learning scheme for the mapping between the } \\
\text { measured grip forces and the driving force/torque imposed on the walker for effective maneuvering. } \\
\text { Tested with } 9 \text { elders. }\end{array}$ \\
\hline [42] & 2015 & $\begin{array}{l}\text { Physical } \\
\text { Support }\end{array}$ & Walker & $\begin{array}{l}\text { A smart walker that can navigate around the environment autonomously by accepting gesture command } \\
\text { from users. A evaluation of the smart walker was performed among } 23 \text { elderly residents. The residents } \\
\text { gave positive feedback but few of them are will to replace their current walker with the proposed smart } \\
\text { walker. The size and weight of the smart walker might be the reason. }\end{array}$ \\
\hline [32] & 2015 & $\begin{array}{l}\text { Physical } \\
\text { Support }\end{array}$ & Walker & $\begin{array}{l}\text { A automatic speed controller for smart walker using ground incline and gait sensor data. Tested with } \\
13 \text { elders and the walker is seen as more comfortable with the speed controller. }\end{array}$ \\
\hline [38] & 2015 & $\begin{array}{l}\text { Physical } \\
\text { Support }\end{array}$ & Exoskeleton & A multi-legged device that can help elders walk and prevent them from falling. \\
\hline [33] & 2015 & $\begin{array}{l}\text { Physical } \\
\text { Support }\end{array}$ & Walker & $\begin{array}{l}\text { A robotics walker with a depth camera that can track and analyze the gait of user in real time by } \\
\text { processing the depth image of user's lower limb. }\end{array}$ \\
\hline [34] & 2013 & $\begin{array}{l}\text { Physical } \\
\text { Support }\end{array}$ & Wheelchair & $\begin{array}{l}\text { An improved particle filter localization algorithm that can improve localization accuracy in a crowded } \\
\text { environment. A trajectory planning method that suits a narrow indoor environment. }\end{array}$ \\
\hline [39] & 2017 & $\begin{array}{l}\text { Physical } \\
\text { Support }\end{array}$ & Other & $\begin{array}{l}\text { An assistant shower system can provide a different level of assistance based on a detected user's } \\
\text { health status. }\end{array}$ \\
\hline [36] & 2017 & $\begin{array}{l}\text { Physical } \\
\text { Support }\end{array}$ & Wheelchair, Review & $\begin{array}{l}\text { A review on development of smart wheelchairs. Different input methods, operation modes and human } \\
\text { factors for smart wheelchairs are reviewed. It also concluded that smart wheelchairs should be } \\
\text { customizable to meet individual user's preference. }\end{array}$ \\
\hline [62] & 2015 & $\begin{array}{l}\text { Physical } \\
\text { Support }\end{array}$ & Wheelchair, Interview & $\begin{array}{l}\text { Interviewed with wheelchair users, manufacturers, therapists and policy makers to explore commercial } \\
\text { viability of smart wheelchairs. The results revealed that smart wheelchairs are not yet accepted by users. } \\
\text { Costs, penalization, and ease-of-use are found to be important. }\end{array}$ \\
\hline$[41]$ & 2019 & $\begin{array}{l}\text { Physical } \\
\text { Support }\end{array}$ & Exoskeleton, Review & $\begin{array}{l}\text { A review on lower currently available lower limb assistive exoskeletons. Technology employed is } \\
\text { thoroughly described. Current exoskeletons are found to be expensive, heavy, and bulky for daily use. }\end{array}$ \\
\hline
\end{tabular}


Table A1. Cont.

\begin{tabular}{|c|c|c|c|c|}
\hline Study & Year & Category & Approaches & Major Outcome \\
\hline$[45]$ & 2016 & $\begin{array}{l}\text { Robot } \\
\text { Ecosystem }\end{array}$ & Mobile Robot & $\begin{array}{l}\text { A mobile robot system IRMA. IRMA can take verbal instructions and find required object within the } \\
\text { home. IRMA can also describe the object's position using furniture's position. High user satisfaction is } \\
\text { achieved in a user study with } 20 \text { participants. Not able to understand sentences containing anaphora. }\end{array}$ \\
\hline [46] & 2013 & $\begin{array}{l}\text { Robot } \\
\text { Ecosystem }\end{array}$ & Mobile Robot & $\begin{array}{l}\text { A method to find human users at home to initiate user interaction. partHOG and motion detection are } \\
\text { used. The algorithm has a high rate of success. Needs long time to compute though. }\end{array}$ \\
\hline [80] & 2013 & $\begin{array}{l}\text { Robot } \\
\text { Ecosystem }\end{array}$ & Machine Learning & $\begin{array}{l}\text { A fast online incremental transfer learning method that can help robots to learn attributes of unknown } \\
\text { objects by transferring attributes information from known objects. }\end{array}$ \\
\hline [47] & 2015 & $\begin{array}{l}\text { Robot } \\
\text { Ecosystem }\end{array}$ & Mobile Robot & $\begin{array}{l}\text { A task allocation system that coordinates multiple heterogeneous robots in highly dynamic real world } \\
\text { environments. Suits better for elder caring facilities than home due to the inherent costs associated with } \\
\text { multiple robots. }\end{array}$ \\
\hline [48] & 2013 & $\begin{array}{l}\text { Robot } \\
\text { Ecosystem }\end{array}$ & Mobile Robot & $\begin{array}{l}\text { Integrate the mobile robot into a smart home environment. The robot can access environment sensors and } \\
\text { provide assistance based on data from sensors. }\end{array}$ \\
\hline [81] & 2013 & $\begin{array}{l}\text { Robot } \\
\text { Ecosystem }\end{array}$ & Mobile Robot & $\begin{array}{l}\text { An experiment to assess older adults' attitude to robot assistance for medication management. The older } \\
\text { adults were open to robot assistance; however, their preferences varied depending on the nature of the } \\
\text { task and perceptions of one's own capability. Social capabilities of robots may also have influence and } \\
\text { need further investigation. }\end{array}$ \\
\hline [44] & 2016 & $\begin{array}{l}\text { Robot } \\
\text { Ecosystem }\end{array}$ & Mobile Robot & $\begin{array}{l}\text { An incremental and online semantic mapping based on HRI. Abstract representation of env. is build and } \\
\text { then be used in task execution. }\end{array}$ \\
\hline [49] & 2018 & $\begin{array}{l}\text { Robot } \\
\text { Ecosystem }\end{array}$ & Robot Integrated System & $\begin{array}{l}\text { A smart home architecture including a mobile robot as assistant. Body sensors, ambient environment } \\
\text { sensors, and mobile robots are used to provide human position tracking, activity monitoring and fall } \\
\text { detection. }\end{array}$ \\
\hline [82] & 2014 & $\begin{array}{l}\text { Robot } \\
\text { Ecosystem }\end{array}$ & Review & $\begin{array}{l}\text { The review found that the majority of robots on the market were entertainment, toys and cleaning robots. } \\
\text { The interface between robot and home automation, home security and other subsystems are missing. }\end{array}$ \\
\hline [83] & 2015 & $\begin{array}{l}\text { Robot } \\
\text { Ecosystem }\end{array}$ & Robot Integrated System & $\begin{array}{l}\text { RUBICON, a "robot ecology" where mobile robot, wireless sensors and other home automation devices } \\
\text { are tightly coupled to provide proper service dynamically. }\end{array}$ \\
\hline [84] & 2017 & $\begin{array}{l}\text { Robot } \\
\text { Ecosystem }\end{array}$ & Mobile Robot & $\begin{array}{l}\text { A mobile robot platform for interactive rehabilitation of disabled persons. Multiple interaction systems } \\
\text { have been integrated, including head gestures, hand gestures, eye tracking, voice, etc.. Moreover, several } \\
\text { applications for rehabilitation training were developed. }\end{array}$ \\
\hline
\end{tabular}


Table A1. Cont.

\begin{tabular}{|c|c|c|c|c|}
\hline Study & Year & Category & Approaches & Major Outcome \\
\hline [5] & 2016 & $\begin{array}{c}\text { Social } \\
\text { Interaction }\end{array}$ & Mobile Robot & Development of evaluation of Hobbit, a social, service and telepresence robot. \\
\hline$[43]$ & 2014 & $\begin{array}{c}\text { Social } \\
\text { Interaction }\end{array}$ & Mobile Robot & $\begin{array}{l}\text { Evaluation of Hobbit, an assistive robot for older people. All participants are targeted older users. } \\
\text { Fetching an object was found as the most important function. }\end{array}$ \\
\hline [4] & 2016 & $\begin{array}{c}\text { Social } \\
\text { Interaction }\end{array}$ & Telepresence Robot & $\begin{array}{l}\text { A 42-month long-term review of mobile robot Giraff regarding the use of in in home environment. } \\
\text { Recommendations from different perspectives found during the evaluation were presented. }\end{array}$ \\
\hline [9] & 2017 & $\begin{array}{c}\text { Social } \\
\text { Interaction }\end{array}$ & Humanoid Robot & $\begin{array}{l}\text { Studies with elderly people regarding using a humanoid robot (NAO) as a fitness coach. Good feedback } \\
\text { from users and mean error of motions for each participants were found to decrease over weekly sessions. } \\
\text { Scoring of motions motivated the elderly. However, the robot is not able to perform all gestures. }\end{array}$ \\
\hline [85] & 2013 & $\begin{array}{c}\text { Social } \\
\text { Interaction }\end{array}$ & Humanoid Robot & $\begin{array}{l}\text { A humanoid robot (NAO) that assists the elderly to perform fitness gestures. The robot can learn fitness } \\
\text { gestures from a human coach and monitor the elderly subject via skeleton analysis. Positive user feedback } \\
\text { for physical exercise. }\end{array}$ \\
\hline [8] & 2014 & $\begin{array}{c}\text { Social } \\
\text { Interaction }\end{array}$ & Humanoid Robot & $\begin{array}{l}\text { Robot that physically coaches, telepresence, vital checks, and informs of dangerous scenarios with system } \\
\text { architecture was proposed and evaluated. The Almere model used to evaluate the perception of robots. } \\
\text { Long-term and cross cultural usage indicated positive results. }\end{array}$ \\
\hline [61] & 2016 & $\begin{array}{c}\text { Social } \\
\text { Interaction }\end{array}$ & Case Study & $\begin{array}{l}\text { An approach to design a social robot by identifying social practices needs to be addressed with input } \\
\text { from caregivers and elders. A case study with the proposed approach. }\end{array}$ \\
\hline [51] & 2016 & $\begin{array}{c}\text { Social } \\
\text { Interaction }\end{array}$ & Review & $\begin{array}{l}\text { A review on how technology can help with older adults' social isolation. The study results show a } \\
\text { positive effect, but studies need to evaluate the effectiveness of addressing senior needs. }\end{array}$ \\
\hline [86] & 2018 & $\begin{array}{c}\text { Social } \\
\text { Interaction }\end{array}$ & Mobile Robot & $\begin{array}{l}\text { A human-like dialogue system for social robot using a finite state interaction model. Positive feedback } \\
\text { from a user study with } 24 \text { participants. }\end{array}$ \\
\hline [84] & 2017 & $\begin{array}{c}\text { Social } \\
\text { Interaction }\end{array}$ & Humanoid Robot & $\begin{array}{l}\text { A robot coach designed based on multi-user engagement models. The proposed robot coach can handle } \\
\text { both 1-on-1 and multiple users interaction. }\end{array}$ \\
\hline [56] & 2014 & $\begin{array}{c}\text { Social } \\
\text { Interaction }\end{array}$ & Telepresence Robot & Proposed an architecture for a telepresence robot. \\
\hline [6] & 2013 & $\begin{array}{c}\text { Social } \\
\text { Interaction }\end{array}$ & Companion Robot & $\begin{array}{l}\text { User study of a communication robot, Matilda, in three aged care facilities. Matilda is able to monitor } \\
\text { positive or negative emotional state. The study results showed that the robot must cross the socio-cultural } \\
\text { barrier for acceptance. }\end{array}$ \\
\hline
\end{tabular}


Table A1. Cont.

\begin{tabular}{|c|c|c|c|c|}
\hline Study & Year & Category & Approaches & Major Outcome \\
\hline [54] & 2013 & $\begin{array}{c}\text { Social } \\
\text { Interaction }\end{array}$ & Dialogue Robot & $\begin{array}{l}\text { A smart home sensor integrated dialogue framework for robot. Enriched dialogue with user can be } \\
\text { achieved by using data collected from sensors. }\end{array}$ \\
\hline [60] & 2018 & $\begin{array}{c}\text { Social } \\
\text { Interaction }\end{array}$ & Augmented Reality & $\begin{array}{l}\text { An AR device to supply info and entertainment for the elderly. Acts as an assistant for scheduling, } \\
\text { medicine reminder, and memory recall. }\end{array}$ \\
\hline [7] & 2013 & $\begin{array}{c}\text { Social } \\
\text { Interaction }\end{array}$ & Companion Robot & $\begin{array}{l}\text { Design and implementation of a communication robot, Matilda. It shows that sensory enrichment } \\
\text { through music, dancing, and emotive expressions are important for a social robot. }\end{array}$ \\
\hline [53] & 2017 & $\begin{array}{c}\text { Social } \\
\text { Interaction }\end{array}$ & Dialogue Robot & A natural language interface that enables users to provide real-time corrections for the behavior of robots. \\
\hline [55] & 2015 & $\begin{array}{c}\text { Social } \\
\text { Interaction }\end{array}$ & Telepresence Robot & Design and implementation of a telepresence robot for supervising and assisting elderly people. \\
\hline [58] & 2013 & $\begin{array}{c}\text { Social } \\
\text { Interaction }\end{array}$ & Companion Robot & $\begin{array}{l}\text { Evaluation of a seal-like companion robot PARO in nursing home with } 10 \text { older adults with dementia. } \\
\text { Positive effects of PARO were found on older adults' activity levels. "Novelty effects" were reported not } \\
\text { an issue, but the trial period was not long enough. }\end{array}$ \\
\hline
\end{tabular}




\section{References}

1. World Population Ageing 2015; Technical Report ST/ESA/SER.A/390; United Nations, Department of Economic and Social Affairs, Population Division: New York, NY, USA, 2015.

2. Groves, M.A.; Wilson, V.F. To move or not to move? Factors influencing the housing choice of elderly persons. J. Hous. Elder. 1993, 10, 33-47. [CrossRef]

3. Sixsmith, A.; Sixsmith, J. Ageing in place in the United Kingdom. Ageing Int. 2008, 32, 219-235. [CrossRef]

4. Orlandini, A.; Kristoffersson, A.; Almquist, L.; Björkman, P.; Cesta, A.; Cortellessa, G.; Galindo, C.; Gonzalez-Jimenez, J.; Gustafsson, K.; Kiselev, A.; et al. ExCITE Project: A review of forty-two months of robotic telepresence technology evolution. Presence Teleoper. Virtual Environ. 2016, 25, 204-221. [CrossRef]

5. Fischinger, D.; Einramhof, P.; Papoutsakis, K.; Wohlkinger, W.; Mayer, P.; Panek, P.; Hofmann, S.; Koertner, T.; Weiss, A.; Argyros, A.; et al. Hobbit, a care robot supporting independent living at home: First prototype and lessons learned. Robot. Auton. Syst. 2016, 75, 60-78. [CrossRef]

6. Khosla, R.; Chu, M.T.; Nguyen, K. Enhancing emotional well being of elderly using assistive social robots in Australia. In Proceedings of the 2013 International Conference on Biometrics and Kansei Engineering, Tokyo, Japan, 5-7 July 2013; pp. 41-46.

7. Khosla, R.; Chu, M.T. Embodying care in Matilda: An affective communication robot for emotional wellbeing of older people in Australian residential care facilities. ACM Trans. Manag. Inf. Syst. 2013, 4, 18. [CrossRef]

8. Torta, E.; Werner, F.; Johnson, D.O.; Juola, J.F.; Cuijpers, R.H.; Bazzani, M.; Oberzaucher, J.; Lemberger, J.; Lewy, H.; Bregman, J. Evaluation of a small socially-assistive humanoid robot in intelligent homes for the care of the elderly. J. Intell. Robot. Syst. 2014, 76, 57-71. [CrossRef]

9. Görer, B.; Salah, A.A.; Akın, H.L. An autonomous robotic exercise tutor for elderly people. Auton. Robots 2017, 41, 657-678. [CrossRef]

10. Lewis, L.; Metzler, T.; Cook, L. Evaluating Human-Robot interaction using a Robot exercise instructor at a senior living community. In Proceedings of the International Conference on Intelligent Robotics and Applications, Tokyo, Japan, 22-24 August 2016; pp. 15-25.

11. Torta, E.; Oberzaucher, J.; Werner, F.; Cuijpers, R.H.; Juola, J.F. Attitudes towards socially assistive robots in intelligent homes: Results from laboratory studies and field trials. J. Hum.-Robot Interact. 2013, 1, 76-99. [CrossRef]

12. Hsieh, Y.H.; Ko, C.H.; Young, K.Y. Obstacle avoidance for passive robot walking helper based on receding horizon control. In Proceedings of the 2016 IEEE International Conference on Systems, Man, and Cybernetics (SMC), Budapest, Hungary, 9-12 October 2016; pp. 550-555.

13. Hsieh, Y.H.; Huang, Y.C.; Young, K.Y.; Ko, C.H.; Agrawal, S.K. Motion guidance for a passive robot walking helper via user's applied hand forces. IEEE Trans. Hum.-Mach. Syst. 2016, 46, 869-881. [CrossRef]

14. Moher, D.; Liberati, A.; Tetzlaff, J.; Altman, D.G.; Group, P. Reprint-Preferred reporting items for systematic reviews and meta-analyses: The PRISMA statement. Phys. Ther. 2009, 89, 873-880. [CrossRef]

15. CADIMA. Available online: https:/ / www.cadima.info/ (accessed on 29 January 2020).

16. Hamdi, O.; Chalouf, M.A.; Ouattara, D.; Krief, F. eHealth: Survey on research projects, comparative study of telemonitoring architectures and main issues. J. Netw. Comput. Appl. 2014, 46, 100-112. [CrossRef]

17. Ihianle, I.K.; Naeem, U.; Tawil, A.R. Recognition of activities of daily living from topic model. Procedia Comput. Sci. 2016, 98, 24-31. [CrossRef]

18. Vasileiadis, M.; Giakoumis, D.; Votis, K.; Tzovaras, D. A Living Lab Infrastructure for Investigating Activity Monitoring Needs in Service Robot Applications. In Proceedings of the 9th ACM International Conference on PErvasive Technologies Related to Assistive Environments, Corfu Island, Greece, 29 June-1 July 2016; p. 72.

19. Tremblay, S.; Fortin-Simard, D.; Blackburn-Verreault, E.; Gaboury, S.; Bouchard, B.; Bouzouane, A. Exploiting Environmental Sounds for Activity Recognition in Smart Homes. In Proceedings of the Workshops at the Twenty-Ninth AAAI Conference on Artificial Intelligence, Austion, TX, USA, 25-26 January 2015.

20. Malazi, H.T.; Davari, M. Combining emerging patterns with random forest for complex activity recognition in smart homes. Appl. Intell. 2018, 48, 315-330. [CrossRef] 
21. Tsai, M.J.; Wu, C.L.; Pradhan, S.K.; Xie, Y.; Li, T.Y.; Fu, L.C.; Zeng, Y.C. Context-aware activity prediction using human behavior pattern in real smart home environments. In Proceedings of the 2016 IEEE International Conference on Automation Science and Engineering (CASE), Fort Worth, TX, USA, 21-25 August 2016; pp. 168-173.

22. Zhang, J.; Wang, Y.; Wang, C.; Zhou, M. Fast Variable Structure Stochastic Automaton for Discovering and Tracking Spatiotemporal Event Patterns. IEEE Trans. Cybern. 2018, 48, 890-903. [CrossRef]

23. Kim, J.Y.; Liu, N.; Tan, H.X.; Chu, C.H. Unobtrusive monitoring to detect depression for elderly with chronic illnesses. IEEE Sens. J. 2017, 17, 5694-5704. [CrossRef]

24. Suryadevara, N.K.; Mukhopadhyay, S.C.; Wang, R.; Rayudu, R. Forecasting the behavior of an elderly using wireless sensors data in a smart home. Eng. Appl. Artif. Intell. 2013, 26, 2641-2652. [CrossRef]

25. Meditskos, G.; Plans, P.M.; Stavropoulos, T.G.; Benois-Pineau, J.; Buso, V.; Kompatsiaris, I. Multi-modal activity recognition from egocentric vision, semantic enrichment and lifelogging applications for the care of dementia. J. Visual Commun. Image Represent. 2018, 51, 169-190. [CrossRef]

26. Zhan, K.; Faux, S.; Ramos, F. Multi-scale conditional random fields for first-person activity recognition on elders and disabled patients. Pervasive Mob. Comput. 2015, 16, 251-267. [CrossRef]

27. Presti, L.L.; La Cascia, M. 3D skeleton-based human action classification: A survey. Pattern Recog. 2016, 53, 130-147. [CrossRef]

28. Toshev, A.; Szegedy, C. Deeppose: Human pose estimation via deep neural networks. In Proceedings of the IEEE Conference on Computer Vision and Pattern Recognition, Columbus, OH, USA, 24-27 June 2014; pp. 1653-1660.

29. Zhu, L.; Zhou, P.; Pan, A.; Guo, J.; Sun, W.; Wang, L.; Chen, X.; Liu, Z. A survey of fall detection algorithm for elderly health monitoring. In Proceedings of the 2015 IEEE Fifth International Conference on Big Data and Cloud Computing, Dalian, China, 26-28 August 2015; pp. 270-274.

30. Withanage, K.I.; Lee, I.; Brinkworth, R.; Mackintosh, S.; Thewlis, D. Fall recovery subactivity recognition with rgb-d cameras. IEEE Trans. Ind. Inform. 2016, 12, 2312-2320. [CrossRef]

31. Sumiya, T.; Matsubara, Y.; Nakano, M.; Sugaya, M. A mobile robot for fall detection for elderly-care. Procedia Comput. Sci. 2015, 60, 870-880. [CrossRef]

32. Shin, J.; Steinmann, I.; Meyer, B. Automatic speed control for SmartWalker. In Proceedings of the 8th ACM International Conference on PErvasive Technologies Related to Assistive Environments, Corfu, Greece, 1-3 July 2015; p. 9.

33. Lim, C.D.; Cheng, C.Y.; Wang, C.M.; Chao, Y.; Fu, L.C. Depth image based gait tracking and analysis via robotic walker. In Proceedings of the 2015 IEEE International Conference on Robotics and Automation (ICRA), Seattle, WA, USA, 26-30 May 2015; pp. 5916-5921.

34. Wang, J.; Chen, W.; Liao, W. An improved localization and navigation method for intelligent wheelchair in narrow and crowded environments. IFAC Proc. Vol. 2013, 46, 389-394. [CrossRef]

35. Miyamoto, H.; Tanaka, T.; Okajima, H.; Matsunaga, N. Experiment of robust driving assistance control for skid steer welfare vehicle using model error compensator. In Proceedings of the 2016 16th International Conference on Control, Automation and Systems (ICCAS), Gyeongju, Korea, 16-19 October 2016; pp. 252-257.

36. Leaman, J.; La, H.M. A comprehensive review of smart wheelchairs: Past, present, and future. IEEE Trans. Hum.-Mach. Syst. 2017, 47, 486-499. [CrossRef]

37. Ryu, H.; Lee, C.; Yoon, H.; Yi, B.J. Smart staff design to assist walking of elders. In Proceedings of the 2016 13th International Conference on Ubiquitous Robots and Ambient Intelligence (URAI), Xi'an, China, 19-22 August 2016; pp. 515-518.

38. Yang, C.; Murakami, T. Walking-assist principle analysis for a multi-legged system. IEEJ J. Ind. Appl. 2015, 4, 294-300. [CrossRef]

39. Ma, M.; Hotrabhavananda, B.; Hall, J.; Skubic, M. Assistive adjustable smart shower system. In Proceedings of the Second IEEE/ACM International Conference on Connected Health: Applications, Systems and Engineering Technologies, Philadelphia, PA, USA, 17-19 July 2017; pp. 253-254.

40. Yang, J.; Li, J.; Bai, D.; Sun, B.; Wang, S. Assistive standing of omni-direetional mobile rehabilitation training robot based on support vector regression algorithm. In Proceedings of the 2016 IEEE International Conference on Information and Automation (ICIA), Ningbo, China, 31 July-4 August 2016; pp. 1050-1055. 
41. Kapsalyamov, A.; Jamwal, P.K.; Hussain, S.; Ghayesh, M.H. State of the Art Lower Limb Robotic Exoskeletons for Elderly Assistance. IEEE Access 2019, 7, 95075-95086. [CrossRef]

42. Shin, J.; Itten, D.; Rusakov, A.; Meyer, B. Smartwalker: Towards an intelligent robotic walker for the elderly. In Proceedings of the 2015 International Conference on Intelligent Environments, Prague, Czech Republic, 15-17 July 2015; pp. 9-16.

43. Körtner, T.; Schmid, A.; Batko-Klein, D.; Gisinger, C. Meeting requirements of older users? Robot prototype trials in a home-like environment. In Proceedings of the International Conference on Universal Access in Human-Computer Interaction, Heraklion, Greece, 22-27 June 2014; pp. 660-671.

44. Gemignani, G.; Capobianco, R.; Bastianelli, E.; Bloisi, D.D.; Iocchi, L.; Nardi, D. Living with robots: Interactive environmental knowledge acquisition. Robot. Auton. Syst. 2016, 78, 1-16. [CrossRef]

45. Wieser, I.; Toprak, S.; Grenzing, A.; Hinz, T.; Auddy, S.; Karaoğuz, E.C.; Chandran, A.; Remmels, M.; El Shinawi, A.; Josifovski, J.; et al. A Robotic Home Assistant with Memory Aid Functionality. In Proceedings of the Joint German/Austrian Conference on Artificial Intelligence (Künstliche Intelligenz), Klagenfurt, Austria, 26-30 September 2016; pp. 102-115.

46. Volkhardt, M.; Gross, H.M. Finding people in apartments with a mobile robot. In Proceedings of the 2013 IEEE International Conference on Systems, Man, and Cybernetics, Manchester, UK, 13-16 October 2013; pp. 4348-4353.

47. Das, G.P.; McGinnity, T.M.; Coleman, S.A.; Behera, L. A distributed task allocation algorithm for a multi-robot system in healthcare facilities. J. Intell. Robot. Syst. 2015, 80, 33-58. [CrossRef]

48. Mozos, O.M.; Tsuji, T.; Chae, H.; Kuwahata, S.; Pyo, Y.; Hasegawa, T.; Morooka, K.; Kurazume, R. The intelligent room for elderly care. In Proceedings of the International Work-Conference on the Interplay Between Natural and Artificial Computation, Mallorca, Spain, 10-14 June 2013; pp. 103-112.

49. Do, H.M.; Pham, M.; Sheng, W.; Yang, D.; Liu, M. RiSH: A robot-integrated smart home for elderly care. Robot. Auton. Syst. 2018, 101, 74-92. [CrossRef]

50. Wilson, R.S.; Krueger, K.R.; Arnold, S.E.; Schneider, J.A.; Kelly, J.F.; Barnes, L.L.; Tang, Y.; Bennett, D.A. Loneliness and risk of Alzheimer disease. Arch. Gen. Psychiatry 2007, 64, 234-240. [CrossRef]

51. Khosravi, P.; Rezvani, A.; Wiewiora, A. The impact of technology on older adults' social isolation. Comput. Hum. Behav. 2016, 63, 594-603. [CrossRef]

52. Mozilla_Privacy Not Included. Available online: https://foundation.mozilla.org/en/privacynotincluded/ about/ (accessed on 30 November 2019).

53. Broad, A.; Arkin, J.; Ratliff, N.; Howard, T.; Argall, B. Real-time natural language corrections for assistive robotic manipulators. Int. J. Robot. Res. 2017, 36, 684-698. [CrossRef]

54. Persson, A.; Coradeschi, S.; Rajasekaran, B.; Krishna, V.; Loutfi, A.; Alirezaie, M. I would like some food: Anchoring objects to semantic web information in human-robot dialogue interactions. In Proceedings of the International Conference on Social Robotics, Bristol, UK, 27-29 October 2013; pp. 361-370.

55. Clotet, E.; Martínez, D.; Moreno, J.; Tresanchez, M.; Palacín, J. Development of a high mobility Assistant Personal Robot for home operation. In Ambient Intelligence-Software and Applications; Springer: Berlin/Heidelberg, Germany, 2015; pp. 65-73.

56. Ghribi, N.; Ammar, B.; Alimi, A.M. Architectural proposal for a mobile telepresence robot, REGIMTEL. In Proceedings of the 2014 6th International Conference of Soft Computing and Pattern Recognition (SoCPaR), Tunis, Tunisia, 11-14 August 2014; pp. 359-364.

57. Shishehgar, M.; Kerr, D.; Blake, J. The effectiveness of various robotic technologies in assisting older adults. Health Inform. J. 2019, 25, 892-918. [CrossRef] [PubMed]

58. Šabanović, S.; Bennett, C.C.; Chang, W.L.; Huber, L. PARO robot affects diverse interaction modalities in group sensory therapy for older adults with dementia. In Proceedings of the 2013 IEEE 13th International Conference on Rehabilitation Robotics (ICORR), Seattle, WA, USA, 24-26 June 2013; pp. 1-6.

59. Broekens, J.; Heerink, M.; Rosendal, H. Assistive social robots in elderly care: A review. Gerontechnology 2009, 8, 94-103. [CrossRef]

60. Yang, Y.; Park, Y.J.; Ro, H.; Chae, S.; Han, T.D. cARe-bot: Portable projection-based AR robot for elderly. In Proceedings of the Companion of the 2018 ACM/IEEE International Conference on Human-Robot Interaction, Chicago, IL, USA, 5-8 March 2018; p. 384. 
61. Rehm, M.; Krummheuer, A.L.; Rodil, K.; Nguyen, M.; Thorlacius, B. From Social Practices to Social Robots-User-Driven Robot Development in Elder Care. In Proceedings of the International Conference on Social Robotics, Kansas City, MO, USA, 1-3 November 2016; pp. 692-701.

62. Padir, T. Towards personalized smart wheelchairs: Lessons learned from discovery interviews. In Proceedings of the 2015 37th Annual International Conference of the IEEE Engineering in Medicine and Biology Society (EMBC), Milan, Italy, 25-29 August 2015; pp. 5016-5019.

63. Baisch, S.; Kolling, T.; Schall, A.; Rühl, S.; Selic, S.; Kim, Z.; Rossberg, H.; Klein, B.; Pantel, J.; Oswald, F.; et al. Acceptance of social robots by elder people: Does psychosocial functioning matter? Int. J. Soc. Robot. 2017, 9, 293-307. [CrossRef]

64. Broadbent, E.; Stafford, R.; MacDonald, B. Acceptance of healthcare robots for the older population: Review and future directions. Int. J. Soc. Robot. 2009, 1, 319. [CrossRef]

65. Bedaf, S.; Marti, P.; Amirabdollahian, F.; de Witte, L. A multi-perspective evaluation of a service robot for seniors: The voice of different stakeholders. Disabil. Rehabil. Assist. Technol. 2018, 13, 592-599. [CrossRef]

66. aibo. Available online: https://us.aibo.com/ (accessed on 8 January 2020).

67. Sharkey, A.; Sharkey, N. Granny and the robots: Ethical issues in robot care for the elderly. Ethics Inf. Technol. 2012, 14, 27-40. [CrossRef]

68. Royakkers, L.; van Est, R. A literature review on new robotics: Automation from love to war. Int. J. Soc. Robot. 2015, 7, 549-570. [CrossRef]

69. Körtner, T. Ethical challenges in the use of social service robots for elderly people. Zeitschrift für Gerontologie und Geriatrie 2016, 49, 303-307. [CrossRef]

70. Vandemeulebroucke, T.; de Casterle, B.D.; Gastmans, C. The use of care robots in aged care: A systematic review of argument-based ethics literature. Arch. Gerontol. Geriatr. 2018, 74, 15-25. [CrossRef]

71. Jacelon, C.S.; Hanson, A. Older adults' participation in the development of smart environments: An integrated review of the literature. Geriatr. Nurs. 2013, 34, 116-121. [CrossRef] [PubMed]

72. Townsend, D.; Knoefel, F.; Goubran, R. Privacy versus autonomy: A trade off model for smart home monitoring technologies. In Proceedings of the 2011 Annual International Conference of the IEEE Engineering in Medicine and Biology Society, Boston, MA, USA, 30 August-3 September 2011; pp. 4749-4752.

73. Frennert, S.; Östlund, B. Seven matters of concern of social robots and older people. Int. J. Soc. Robot. 2014, 6, 299-310. [CrossRef]

74. Ordóñez, F.; de Toledo, P.; Sanchis, A. Activity recognition using hybrid generative/discriminative models on home environments using binary sensors. Sensors 2013, 13, 5460-5477. [CrossRef] [PubMed]

75. Demir, E.; Köseoğlu, E.; Sokullu, R.; Şeker, B. Smart home assistant for ambient assisted living of elderly people with dementia. Procedia Comput. Sci. 2017, 113, 609-614. [CrossRef]

76. Aramendi, A.A.; Weakley, A.; Goenaga, A.A.; Schmitter-Edgecombe, M.; Cook, D.J. Automatic assessment of functional health decline in older adults based on smart home data. J. Biomed. Inform. 2018, 81, 119-130. [CrossRef] [PubMed]

77. Chen, Y.H.; Tsai, M.J.; Fu, L.C.; Chen, C.H.; Wu, C.L.; Zeng, Y.C. Monitoring elder's living activity using ambient and body sensor network in smart home. In Proceedings of the 2015 IEEE International Conference on Systems, Man, and Cybernetics, Hong Kong, 9-12 October 2015; pp. 2962-2967.

78. Stavropoulos, G.; Giakoumis, D.; Moustakas, K.; Tzovaras, D. Automatic action recognition for assistive robots to support MCI patients at home. In Proceedings of the 10th International Conference on PErvasive Technologies Related to Assistive Environments, Rhodes, Greece, 21-23 June 2017; pp. 366-371.

79. Salah, O.; Sessa, S.; El-Bab, A.M.F.; Kobayashi, Y.; Takanishi, A.; Fujie, M. Modeling and simulation for support robot tracking a human sit to stand motion. In Proceedings of the 2016 28th International Conference on Microelectronics (ICM), Cairo, Egypt, 17-20 December 2016; pp. 81-84.

80. Hasegawa, O.; Kimura, D. Home robots, learn by themselves. In Proceedings of the International Conference on Universal Access in Human-Computer Interaction, Las Vegas, NV, USA, 21-26 July 2013; pp. 48-53.

81. Prakash, A.; Beer, J.M.; Deyle, T.; Smarr, C.A.; Chen, T.L.; Mitzner, T.L.; Kemp, C.C.; Rogers, W.A. Older adults' medication management in the home: How can robots help? In Proceedings of the 8th ACM/IEEE International Conference on Human-Robot Interaction, Tokyo, Japan, 3-6 March 2013; pp. 283-290.

82. Doelling, K.; Shin, J.; Popa, D.O. Service robotics for the home: A state of the art review. In Proceedings of the 7th International Conference on PErvasive Technologies Related to Assistive Environments, Island of Rhodes, Greece, 27-30 May 2014; p. 35. 
83. Amato, G.; Bacciu, D.; Broxvall, M.; Chessa, S.; Coleman, S.; Di Rocco, M.; Dragone, M.; Gallicchio, C.; Gennaro, C.; Lozano, H.; et al. Robotic ubiquitous cognitive ecology for smart homes. J. Intell. Robot. Syst. 2015, 80, 57-81. [CrossRef]

84. Gomez-Donoso, F.; Orts-Escolano, S.; Garcia-Garcia, A.; Garcia-Rodriguez, J.; Castro-Vargas, J.A.; Ovidiu-Oprea, S.; Cazorla, M. A robotic platform for customized and interactive rehabilitation of persons with disabilities. Pattern Recognit. Lett. 2017, 99, 105-113. [CrossRef]

85. Görer, B.; Salah, A.A.; Akın, H.L. A robotic fitness coach for the elderly. In Proceedings of the International Joint Conference on Ambient Intelligence, Dublin, Ireland, 3-5 December 2013; pp. 124-139.

86. Manuhara, G.M.; Muthugala, M.V.J.; Jayasekara, A.B.P. Design and Development of an Interactive Service Robot as a Conversational Companion for Elderly People. In Proceedings of the 2018 Moratuwa Engineering Research Conference (MERCon), Moratuwa, Sri Lanka, 29-31 May 2018; pp. 378-383.

(C) 2020 by the authors. Licensee MDPI, Basel, Switzerland. This article is an open access article distributed under the terms and conditions of the Creative Commons Attribution (CC BY) license (http:/ / creativecommons.org/licenses/by/4.0/). 